\title{
PRÁTICAS EDUCATIVAS DEMOCRÁTICAS
}

\author{
Pedro Manuel Patacho*
}

\begin{abstract}
RESUMO: O presente texto constitui uma reflexão teórica acerca da instituição escolar, entendida como uma instituição democrática. Partindo de uma análise crítica dos propósitos da escolarização, utilizaremos o conceito de currículo oculto para rejeitar um entendimento neutro e objectivo, tanto do currículo como das práticas educativas, reflectindo depois em torno de possibilidades alternativas de trabalho numa escola, cujas práticas possam beber de uma cultura democrática de pluralismo agonístico, porém, práticas educativas construídas a partir de baixo, de forma dialógica, a partir das culturas e das vivências das crianças e dos jovens, das suas famílias, da comunidade, segundo uma ideia de resistência quotidiana às forças de dominação, numa contínua busca de maior justiça social e curricular. Neste contexto, os educadores são perspectivados como activistas sociais.
\end{abstract}

Palavras-chave: Escola. Democracia. Políticas educativas. Acção comunitária. Justiça social.

\section{DEMOCRATIC EDUCATIONAL PRACTICES}

ABSTRACT: This paper reflects on the school as a democratic institution. Beginning with a critical analysis of the purposes of schooling, we use the concept of hidden curriculum to reject an objective and neutral understanding of both the curriculum and educational practices. We then ponder about alternative possibilities of working in schools whose practices are deeply grounded in a plural agonistic democratic culture. Yet, these should be bottom-up, dialogical educational practices based on the culture and everyday life of children and youth, their families and communities, following an idea of everyday resistance to the domination forces, in the constant pursuit of more social and curricular justice. In this context, educators are described as social activists.

Key words: School. Democracy. Educational policies. Community action. Social justice.

\section{Pratiques Éducatives démocratiques}

RÉSUMÉ: Ce texte présente une réflexion théorique sur l'école en tant qu'institution démocratique. A partir d'une analyse critique des buts de la scolarisation, nous reprenons le concept de curriculum caché pour rejeter une compréhension

* $\quad$ Doutorando em Didáctica e Organização Escolar na Universidade de Coruña (Espanha) e professor adjunto no Instituto Superior de Ciências Educativas, Portugal. E-mail: ppatacho@yahoo.com 
neutre et objective et du curriculum et des pratiques éducatives. Nous nous penchons ensuite su les possibilités alternatives de travail dans une école dont les pratiques pourraient puiser dans une culture démocratique de pluralisme agonistique tout en étant construites de la base vers le sommet et de manière dialogique, à partir des cultures et des vécus des enfants, des jeunes, de leur famille et de leur communauté, conformément à une idée de résistance quotidienne aux forces de domination, en une recherche continue de plus de justice sociale e curriculaire. Dans un tel contexte, les éducateurs sont dépeints comme des activistes sociaux.

Mots-clefs: École. Démocratie. Politiques éducatives. Action communautaire. Justice sociale.

\section{Introdução}

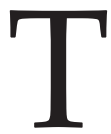

ornou-se lugar comum dizer que esta Escola que temos hoje é uma instituição desfasada da realidade social e das necessidades actuais. Tornou-se lugar comum questionar a educação escolar, afirmar a inutilidade dos professores, questionar o seu conhecimento profissional e colocar definitivamente em causa a importância do seu trabalho com as comunidades locais e as gerações mais jovens. A educação escolar está, mais do que nunca, debaixo de fogo. Ao mesmo tempo, não é menos verdade que muitos professores olham para a escola de hoje com uma enorme desilusão e desmotivação. Pressionados pela administração, questionados pelas famílias, desacreditados pelos órgãos de comunicação, os professores enfrentam hoje uma das mais duras batalhas das suas vidas no seio da escola pública: recuperar o seu prestígio profissional, mergulhar profundamente nas comunidades locais e afirmar o papel central da educação escolar na construção da cidadania democrática para o século xxI, crítica, activa e responsável. Do nosso ponto de vista, o caminho para travar essa batalha assenta num entendimento político da educação, o que nos obriga a abordar as problemáticas da escolarização sem passar por cima do conceito de ideologia e de um entendimento das relações sociais como relações de poder.

Procuramos neste texto reflectir criticamente acerca da escola, quando entendida como instituição democrática. Partindo duma análise dos propósitos da instituição escolar, utilizaremos o conceito de currículo oculto para rejeitar um entendimento neutro e objectivo do currículo e das práticas educativas, reflectindo depois em torno de outras possibilidades de trabalho numa escola, cujas práticas possam beber de uma cultura democrática de pluralismo agonístico, porém, práticas educativas construídas a partir de baixo, de forma dialógica, segundo uma ideia de resistência quotidiana às forças de dominação, numa contínua busca de maior justiça social e curricular, em que os educadores são perspectivados como activistas sociais. 


\section{A instituição escolar}

Que escola obrigatória temos hoje? Apoiando-nos no brilhante raciocínio de Zinn e Macedo (2007) sobre as contradições de uma realidade educativa que é assustadoramente transnacional, diríamos que temos uma escola que se propõe a promover a democracia, mas que ao mesmo tempo funciona e está estruturada de maneiras que minam constantemente os princípios democráticos essenciais que afirma promover. Temos uma escola que afirma defender os valores da solidariedade, da equidade e da justiça, mas que, ao mesmo tempo, prepara as crianças e os jovens para aceitarem a exploração social endémica e as absurdas contradições sociais que mantêm oprimidas largas camadas sociais. Com efeito, não é proporcionada aos menores uma visão exacta da divisão de classes e da forma obscena como o dinheiro domina todos os aspectos das sociedades contemporâneas, em que impera um neoliberalismo predatório sem precedentes na história da humanidade. Temos uma escola essencialmente regulada por padrões de valor cultural eurocêntricos, brancos, burgueses e heterossexuais. Temos uma escola que afirma ser livre e emancipadora, mas que, na verdade, se alia às lógicas da performance, na mais pura subordinação às pragmáticas necessidades do mercado de trabalho. Algo que não deverá ser surpreendente se pensarmos que é precisamente nos momentos históricos em que "os movimentos sociais estão mais debilitados e em que a ideologia empresarial é forte [que] as escolas tendem a fortalecer a sua função de reproduzir trabalhadoras e trabalhadores para desempenharem com submissão os seus papéis laborais" (Carnoy \& Levin, 1985, p. 75) no seio das sociedades capitalistas, aceitando pacificamente as relações laborais baseadas numa desigual divisão do trabalho.

A que interesses serve esta escola? Certamente que não são os de todo um mundo de diversidade social e cultural que é frequentemente ignorado. Na verdade, à medida que há cada vez mais diversidade de alunos nas escolas e salas de aula, nem os currículos nem as práticas escolares os têm em consideração. Nos sistemas educativos contemporâneos

(...) são muitas as alunas e os alunos que não se sentem reconhecidos nas aulas [e em todo o trabalho escolar] porque, entre outros aspectos, os grupos sociais, culturais, linguísticos e étnicos a que pertencem não existem nos conteúdos culturais trabalhados nas aulas, nem em qualquer um dos recursos didácticos com os quais realizam as suas tarefas escolares. (Torres, 2010, p. 23)

Enfrentando uma cultura escolar que choca violentamente com a sua cultura familiar, muitos alunos constroem rapidamente um forte sentido de aversão a uma escola que simplesmente não os compreende, para além de ensaiar medidas compensatórias que são, em si mesmas, ignorantes das complexas problemáticas que ocultam o seu insucesso (ou melhor, a sua dificuldade de acesso) e o seu desinteresse. Esta é, 
mais vezes do que as que desejaríamos, uma escola desinteressante, autoritária e ignorante, onde se alastram injustiças sociais e educativas sem precedentes, uma escola normalizadora e amestradora que aparece como uma rotunda desilusão quando perspectivada como instituição democrática. Mais a frente, apoiados no conceito de currículo oculto, tal como desenvolvido por Torres (1998), tentaremos explicar estas contradições, que por agora apenas designaremos de aparentes.

É possível afirmar - ainda que correndo o risco de o fazer de uma forma demasiado simples - que a configuração da instituição escolar tal como a conhecemos actualmente, como núcleo dos sistemas educativos modernos, tem lugar como resposta às profundas tensões económicas, sociais e políticas que resultaram do advento da Revolução Industrial. Nas modernas sociedades capitalistas, os grupos sociais que detinham o poder perceberam cedo que a perpetuação da sua condição privilegiada exigia a subordinação de uma vasta maioria que era necessário controlar, a fim de que não se tornasse problemática e mantivesse a sua utilidade no processo de consolidação da democracia burguesa (Saviani, 2008). Porém, havia que o fazer com subtileza, dada a necessidade crescente de uma mão-de-obra que, para além de dócil, se exigia cada vez mais qualificada. As escolas desempenharam aqui um importante papel. Daí que os seus principais propósitos não foram nunca transformadores, mas, bem pelo contrário, reprodutores (Bourdieu \& Passeron, 2009), lidando com as insuperáveis contradições de uma ordem socioeconómica injusta que se impôs com um poder avassalador. Não faltaremos à verdade se afirmarmos que, ainda que entendida de uma forma bastante ampla, tem sido esta a função social desempenhada pelas instituições escolares que, incapazes de superar as seculares tensões que lhes subjazem, não fazem mais do que reproduzir os seus efeitos.

Contudo, ao longo de mais de um século, sempre houve vozes a ecoar em outras direcções. Numa época em que a ideologia da "eficiência social" se impunha como força educativa dominante, Dewey (2007), entre tantos outros, entendeu a educação e as escolas de um modo muito diferente. Para ele, a educação tinha que ser um modo de vida e não um mero meio de preparação para a vida, como também veio a afirmar Kilpatrick (2006). Não podia ser algo imposto às crianças e aos jovens, mas, muito pelo contrário, corresponder ao desabrochar das capacidades inatas de cada um, a uma contínua construção e reconstrução de experiências. A sua visão da educação assentava essencialmente na importância da prática e no valor fundamental da democracia, enfatizando a imperiosa necessidade de a escola ser uma expansão, completa e livre, das experiências de vida de cada criança e de cada jovem, através da edificação de condições para que os alunos e as alunas participassem activamente na construção do meio e da cultura, o que se traduz na habilidade de cada um ser constantemente capaz de expandir a sua cultura. Escrevia Dewey, em 1922, que 
(...) a democracia não será democracia enquanto a principal preocupação da educação não for a libertação de aptidões individuais em termos artísticos, intelectuais e em termos de companheirismo humano (...). O hábito de classificar e de comparar em função de aspectos quantitativos tem sido (...) o obstáculo intelectual impedindo que isto aconteça. (2009, p. 12)

Segundo o pensamento deste importante autor, a escola seria um espaço social no qual cada indivíduo criaria e implementaria o seu próprio processo e percurso de aprendizagem, um espaço livre que permitiria a cada um a edificação do seu próprio caminho. Dewey entendia que a instituição escolar devia assumir-se abertamente como transformadora da ordem social instituída, garantindo a concretização plena dos valores democráticos. Seria esta a sua função social fundamental. Ainda que baseado numa perspectiva de democracia que emerge da confluência de interesses partilhados e, portanto, de consensos, o pensamento educativo do autor é notável e mostra-nos outra visão da escola, embora tenhamos que ir muito para além de Dewey para vislumbrar uma escola e um trabalho escolar que resistam à dominação cultural.

Porém, do que acaba de ser dito, acerca da institucionalização do ensino num momento histórico preciso e das resistências de importantes intelectuais como Dewey, resulta claro que as instituições escolares e as políticas educativas não podem ser compreendidas de forma isolada, descontextualizadas de um enquadramento sócio-histórico concreto, em que ganha verdadeiro sentido aquilo que elas são. Em cada período histórico, os sistemas educativos e as instituições escolares desempenham um papel primordial na legitimação das ideias, visões e projectos das classes que detêm o poder para decidir aquilo que devem ser e o que devem fazer as escolas e outras instituições. Mas, apesar disto, "o mito mais importante em que assenta a planificação e o funcionamento do sistema educativo nos países capitalistas é o da neutralidade e objectividade do sistema e, por conseguinte, da escolarização" (Torres, 1998, p. 14). Petante a continuada afirmação deste mito, fortemente aliada à ideia de que as instituições escolares que temos são as únicas possíveis e as mais adequadas para fazer face às necessidades dos tempos em que vivemos, é fácil perder de vista que a escolarização, tal como a concebemos hoje, é na verdade uma construção social e histórica no seio de dinâmicas de poder muito bem orquestradas, o resultado de inúmeras tensões que vieram a desembocar numa realidade cultural que podia, com efeito, ter sido outra (Viñao, 2007).

\section{Atenção ao currículo oculto}

A criação, recriação e manutenção de uma determinada ordem socioeconómica e sociocultural, na qual as instituições escolares desempenharam e seguem desempenhando um papel preciso de reprodução social, económica e cultural, em vez de 
transformação, só podem ser cabalmente entendidas se relacionadas com o conceito de ideologia que, tal como definido por Therborn (1987, p. 15-16), "qualifica e define os sujeitos dizendo-lhes, fazendo-lhes reconhecer e relacionando-os com o que existe, (...) o que não existe, (...) o que é bom, correcto, justo, bonito, atraente, agradável, assim como todos os seus contrários, (...) o que é possível e impossível (...)".

Como destaca Torres (1998, p. 18 e 19), uma ideologia traduz toda "uma visão do mundo, uma perspectiva sobre as coisas, acontecimentos e comportamentos (....)" e manifesta-se "tanto nas ideias como nas práticas das pessoas (...)", conferindo às cidadãs e aos cidadãos

(...) a partilha de um sentido de pertença, uma identidade que os torna conscientes das possibilidades e limitações dos seus actos, estrutura e normaliza os seus desejos e, ao mesmo tempo, proporciona uma explicação das transformações e das consequências das mudanças (...) o que implica entendimentos sobre o próprio ser individual e as suas relações com os outros grupos humanos e com a sociedade em geral. (p. 19)

Mesmo que as pessoas não possuam a percepção da "relação dialéctica entre a consciência individual e as estruturas sociais" (idem), a ideologia opera subtilmente, criando entre aqueles que a partilham "uma espécie de senso comum que, por sua vez, tem uma correspondência na prática através de comportamentos individuais e colectivos" (idem). É neste sentido que a hegemonia ideológica, tal como proposto por Gramsci (1991), trabalha astutamente para impor aos grupos sociais significados e possibilidades de acção que contribuam para manter a ordem socioeconómica estabelecida, deixando intactas as complexas relações de poder nela ocultas, baseadas na dominação de classe e na perpetuação das relações sociais de produção e distribuição (Torres, 1998).

As instituições escolares surgiram, portanto, como um importante cenário de doutrinação ideológica de crianças e jovens, para assim garantir, desde cedo, a aceitação pacífica das ordens socioeconómica e sociocultural estabelecidas, o que quer dizer, mais precisamente, a aquiescência daqueles face aos desígnios dos grupos sociais dominantes e, mais importante, a legitimação destes na sua condição privilegiada. Os discursos educativos dominantes, aparentemente desinteressados, constituíram na verdade um poderoso instrumento ideológico que encontrou a sua legitimidade e primazia incontestáveis no advento das chamadas Ciências da Educação - fortemente influenciadas pela Psicologia -, cujo contributo para a dissimulação dos conflitos inerentes a qualquer sociedade capitalista foi decisivo, colocando a tónica, em vez de nesses conflitos, na promoção de conhecimentos socialmente úteis, porque eficazes no mercado de trabalho em crescimento exponencial, na necessidade de objectividade, na mensurabilidade, nos standards e em valores como o individualismo, o esforço, a eficiência e o mérito. 
Compreende-se assim a importância, no momento de analisar os sistemas educativos e aquilo que as crianças e os jovens aprendem nas escolas, de prestar atenção não apenas ao currículo oficial, mas muito especialmente ao currículo oculto. O currículo oculto de cada instituição escolar concreta, ao contrário do currículo oficial, nunca aparece realmente explícito na forma de metas educativas a alcançar, sendo composto, mais precisamente, por "todos os conhecimentos, capacidades, atitudes e valores que se adquirem mediante a participação nos processos de ensino e aprendizagem e, em geral, em todas as interacções que têm lugar no dia-a-dia das aulas e nas instituições escolares" (Torres, op. cit, p. 190) e que contribuem de forma subtil "para o reforço dos conhecimentos, procedimentos, valores e expectativas consonantes com as necessidades e os interesses da ideologia hegemónica" (idem, ibid.) de um determinado momento sócio-histórico.

Pensando desta forma, percebemos claramente como as contradições identificadas por Zinn e Macedo, anteriormente referidas, são assustadoramente reais. As instituições escolares privilegiam realmente uma cultura eurocêntrica dominante, classista, branca, masculina e heterossexual. A influência que nelas tem o modelo de desenvolvimento económico capitalista (hoje nas suas versões neoliberais predatórias) força-as no sentido de privilegiarem o individualismo, a competição, a cultura do esforço, a selecção dos mais capazes. Não se trata, pois, de uma escola dialogante, realmente democrática, solidária, integradora, comunitária, descomplexada, culturalmente rica, expressiva e criativa, como tantas vezes se perspectiva nos documentos oficiais. Então, por que designámos anteriormente de "aparentes" estas contradições que agora afirmamos serem uma realidade? Porque essas incoerências entre os princípios educativos e as práticas escolares são na verdade o resultado óbvio de uma escola que, como instrumento ideológico projectado pelas classes dominantes, constitui um mecanismo que visa garantir a perpetuação dos seus interesses (Althusser, 1988).

Isso faz com que ocorra frequentemente um choque entre as culturas dos estudantes e a cultura da escola. Este impacto é ainda mais intenso quando consideramos as crianças e os jovens oriundos de minorias ou das classes populares mais desfavorecidas. Os seus valores, as suas visões do mundo, a sua vida em geral não se enquadra nas categorias de análise e de classificação privilegiadas pela escola. Estas crianças e jovens vêem-se na dura realidade de terem de escolher entre a sua identidade cultural e a subordinação aos padrões culturais veiculados como superiores, que devem tentar, com esforço, adquirir. Perante esta situação culturalmente violenta e socialmente injusta, muitos jovens são incapazes de ultrapassar as fronteiras culturais (Giroux, 1992) impostas pela instituição escolar e de alcançar sucesso educativo. Trata-se, mais precisamente, de um problema de acesso que é habilidosamente apresentado como insucesso, ao ocultar as questões sociopolíticas envolvidas. Os 
alunos que conseguem ser bem sucedidos fazem-no porque estão em sintonia com os padrões de valor cultural veiculados pela escola, ou porque aprendem a jogar as regras deste jogo cultural, à medida que reprimem os seus desejos e aspirações e desvalorizam a sua cultura familiar e popular, na busca de um ideal de sucesso que, ainda que não se apercebam, lhes é imposto como aquele que devem seguir.

\section{Possibilidades de resistência}

Resistir não é fácil. Alcançar práticas educativas mais democráticas, que tenham em atenção todo o mundo de diversidade cultural que é frequentemente ignorado pelas escolas e que ainda assim preparem as crianças e os jovens de acordo com as exigências dos documentos oficiais, é uma tarefa complexa. Superar as injustiças sociais que se reproduzem nas escolas e, mais ainda, desenvolver a partir das instituições escolares uma acção educativa transformadora, que contribua para alterar as condições sociais que originam e mantêm a injustiça e a descriminação endémicas, parece, na maior parte das vezes, verdadeiramente impossível. Daí a importância de perceber que a simples ideia dessa impossibilidade é, na verdade, o resultado esperado do poder esmagador da hegemonia ideológica que opera de forma hábil para manter os educadores democráticos de mãos e pés bem atados.

As pressões de cima para baixo são fortíssimas na regulação de toda a vida social e na imposição de padrões de valor cultural, ao ponto de os indivíduos perderem a noção de como os seus desejos, crenças e aspirações são na realidade manufacturados e socialmente condicionados. Como constata Torres (1998, p. 199), as escolas estão desenhadas "para transmitir certos conteúdos culturais com a finalidade de preparar os membros mais jovens de cada sociedade específica para, no futuro, desempenharem aqueles papéis de que necessita um modelo de sociedade definido segundo os interesses dos grupos sociais dominantes". Portanto, o primeiro passo para uma verdadeira possibilidade de resistência consiste na consciencialização desta realidade, no entendimento das relações sociais como relações de poder (Mouffe, 2006). Essa tomada de consciência pode encontrar terreno fértil no seio da relativa autonomia de que ainda goza o trabalho escolar para forçar verdadeiros rasgos democráticos nas fissuras contraditórias que sempre existem nos processos de produção e reprodução dos produtos culturais.

Como Torres (1998, p. 199) nos chama a atenção, "o desenvolvimento do currículo oculto nem sempre trabalha na direç̧ão de uma consolidação dos interesses dos grupos sociais dominantes e das estruturas de produção e distribuição vigentes". A análise das práticas quotidianas, que se pode observar, por exemplo, no importante trabalho de Certeau (1984), revela-nos as maneiras como as pessoas actuam no seu quotidiano, nos vários espaços e tempos da sua existência, como fazem as 
coisas e como as fazem com os outros, nas circunstâncias relacionais incoerentes e muitas vezes contraditórias em que se movem todos os dias da sua vida, num contexto de dominação que pode ser habilmente combatido. É naquelas incoerências e contradições, de que já falámos relativamente à instituição escolar, que se jogam as possibilidades antagónicas. Dito de outra forma, é nessas contradições que se abre o espaço para a resistência contra-hegemónica.

Todas as pessoas têm a extraordinária capacidade quotidiana de, ao contrário de aceitar passivamente os padrões culturais dominantes impostos pelas instituições em que passam parte substancial do seu tempo vital, fazer algo bem diferente do que é de si esperado. Não se trata da subversão de tais padrões culturais, mas de usálos para o enfraquecimento do seu próprio poder. Certeau (1984) propõe-nos uma prática anti-disciplina, uma micro-resistência quotidiana através do uso habilidoso daquilo que é imposto a favor de uma nova produção cultural, a saber, a das pessoas comuns, os heróis quotidianos e anónimos cuja acção diária pode fazer a diferença. Voltaremos a esta ideia mais adiante para reafirmar a importância do que passamos a descrever como práticas educativas construídas a partir de baixo, como possibilidade de resistência, e para perspectivar os professores como activistas sociais, como agentes de transformação social contra a injustiça e pela equidade.

A abertura daqueles rasgos democráticos a que nos referimos anteriormente, ou esta resistência quotidiana a que nos referimos agora, requer a adopção de práticas educativas mais consonantes com os valores democráticos. Por um lado, é importante questionar a fragmentação da cultura escolar, muito relacionada com a fragmentação dos processos de produção e com uma lógica educativa subordinada às necessidades económicas ditadas pelo mercado, como destaca Torres (2000, p. 148-149), para poder vislumbrar que, se quisermos "preparar sujeitos activos, críticos, solidários e democráticos para uma sociedade [injusta] que queremos transformar (...)", então é necessário que

(...) as aulas e as instituições escolares se convertam num espaço onde essa mesma sociedade que nos rodeia é submetida à revisão crítica todos os dias e no qual se desenvolvam aquelas capacidades imprescindíveis à participação e melhoria da comunidade concreta e específica de que se faz parte. (Idem, p. 149)

Trata-se de edificar práticas educativas em que a discriminação e a injustiça estejam constantemente sob análise "em todo o trabalho escolar, todos os dias, em todas as tarefas académicas e em todos os recursos didácticos" (p.151). Dito de outra forma, trata-se de viver intensamente os princípios democráticos em todo o trabalho escolar e de submeter constantemente a sociedade actual a uma revisão crítica.

A construção de tais práticas educativas democráticas, em que as crianças e os jovens consigam "desmascarar as dinâmicas políticas, históricas e semióticas que 
condicionam as suas interpretações, expectativas e possibilidades de intervir na realidade" (p. 151), é apenas possível com a rejeição liminar da fragmentação do conhecimento que apenas serve os interesses dos grupos dominantes que necessitam de ver supridas as necessidades económicas de produção. Resulta claro, então, que o caminho para uma educação mais democrática repousa numa visão integrada do currículo e da educação, de resto, mais consonante até com a própria natureza holística do conhecimento e com a idiossincrasia dos processos de aprendizagem, como demonstra Torres (2000), apoiado no imenso trabalho produzido pelos teóricos da aprendizagem. Como também destaca Bean (1997), a ideia de integração curricular surge de forma natural como o núcleo de uma educação mais democrática (centrada não apenas nas desigualdades e nas injustiças, mas sobretudo nas condições particulares que as geram e as mantêm, para daí edificar uma educação na e para a acção transformadora), que emerge da "intersecção de preocupações pessoais das crianças e dos jovens com preocupações sociais mais vastas" (Bean, op. cit., p. 48), onde são encontrados e definidos os temas curriculares, bem como as reais possibilidades de acção democrática.

Por outro lado, é igualmente importante que as professoras e os professores assumam de forma clara a educação como um compromisso político "pela justiça social, pela igualdade e pela democracia" (Torres, 2001, p. 242) e que esse compromisso esteja bem patente na sua acção. A prática educativa, perspectivada "como trabalho cultural, social, ético e político, implica a participação dos cidadãos e das cidadãs (...) através das organizações nas quais se reúnem" (p. 235). Portanto, essa participação de todos na consolidação de uma educação mais democrática requer uma verdadeira cultura de colaboração, tanto entre docentes e discentes, como entre as instituições escolares, as famílias e demais organizações sociais interessadas na educação e na luta contra as desigualdades sociais. Trata-se, mais precisamente, de perspectivar a educação como activismo social e os actores educativos como activistas sociais, como enfatiza Torres (op. cit.).

Os dois aspectos a que se acaba de fazer referência são essenciais para a edificação de práticas educativas mais democráticas, segundo uma perspectiva agonística de democracia que "requer entender o facto de que o poder é constitutivo das relações sociais" (Mouffe, 2006, p. 24), pelo que é imperioso reconhecer "a dimensão do antagonismo e o seu carácter inerradicável [das relações humanas], que decorre do pluralismo de valores" (idem ibid.) característico das sociedades contemporâneas. É fundamental dialogar de forma séria e descomplexada nas instituições escolares, pois só com instituições, discursos e formas de vida que fomentem os valores democráticos será possível educar cidadãos democráticos não "abstraídos das relações sociais de poder, linguagem, cultura e todo um vasto conjunto de práticas que tornam o agenciamento possível" (ibid., p. 20). Não para construir consensos - que não são mais do que a exacta expressão da exclusão resultante 
de relações desequilibradas de poder -, mas sim para desencadear a paixão pelo político. Quando a escola se define de forma clara, a partir de cima, ela é simultaneamente uma escola que exclui, eliminando à partida as suas possibilidades de vir a ser, para se converter num produto acabado e alienante.

É por isso que as possibilidades de resistência, numa escola cujas práticas possam beber de uma cultura democrática de pluralismo agonístico, têm de ser construídas a partir de baixo, das culturas e das vivências das crianças e dos jovens, das suas famílias, da comunidade, segundo uma ideia de resistência quotidiana, numa contínua busca de maior justiça social e educativa. Chegamos aqui apoiados também no incontornável pensamento de Boaventura de Sousa Santos, quando afirma que nas sociedades contemporâneas as instituições democráticas como a escola estão a braços com a evidente "não realização prática dos valores da liberdade, da igualdade e da solidariedade" (Santos, 2006, p. 25), tal como prometido pelo ideal moderno, donde resulta a "necessidade de reinventar a emancipação social (...) partindo das ideias e concepções que (...) foram marginalizadas pelas concepções dominantes" (idem, ibid.). Tal desígnio, adianta o autor, só pode ser alcançado a partir de baixo, a partir das experiências dos grupos sociais que viram as suas possibilidades emancipatórias reduzidas às "tornadas possíveis pelo capitalismo, uma redução que (...) transformou a emancipação social no duplo, e não no contrário, da regulação social” (ibid.), o que possibilitará a emergência de novas epistemologias locais contra-hegemónicas.

As implicações do pensamento de Boaventura para a concepção de práticas educativas transformadoras são enormes. Com efeito, é necessário que a edificação de uma educação democrática que reconheça o pluralismo de valores das sociedades actuais e a natureza agonística das relações sociais se ampare na expressão viva desse pluralismo e na emergência de produtos culturais específicos de cada pessoa, de cada grupo social e de cada contexto local, proporcionando uma vivência educativa que desoculte as complexas dinâmicas de poder, que criam e mantêm as situações de injustiça, ao mesmo tempo que geram alienação. Deverá ser esta a luta quotidiana das escolas democráticas e das educadoras e educadores democráticos, num esforço contínuo para a transformação das condições injustas de cada contexto local.

É nesta perspectiva que as análises de Certeau (1984) são importantes, pois incentiva-nos a pensar as práticas quotidianas na escola como um terreno primordial de desenvolvimento da pessoa como ser produtor de cultura, desviando a nossa atenção dos produtos culturais recebidos e impostos para redefinirmos as nossas prioridades, a favor da criação cultural anónima e quotidiana, segundo a vontade de cada pessoa. Encontrar sentidos nas artes de fazer de professores e de alunos e aceitar a legitimidade dos saberes e dos valores que emergem de tais práticas locais do colectivo escolar, das suas estratégias e tácticas próprias são talvez o maior desafio da educação democrática, acreditando firmemente na liberdade da prática, na 
valorização da diferença e na percepção das possibilidades de resistência que emergem das liberdades anónimas, capazes de empurrar as fronteiras da dominação à medida que edificam uma sólida consciência crítica. Toda a actividade humana é cultura, quando as práticas sociais têm significado claro para aquele que as realiza. E é através da sua acção que cada um - e todos colectivamente - pode contribuir para a manutenção de uma determinada visão do mundo ou para a sua transformação.

Isso nos faz pensar também que a edificação das epistemologias locais terá de conseguir ir para além das experiências dos grupos sociais que viram as suas possibilidades emancipatórias reduzidas. Diríamos mesmo que, para alcançarem a justiça social e educativa nas sociedades contemporâneas, terão forçosamente que o fazer, perante um neoliberalismo predatório que não apenas conseguiu reinventar as seculares desigualdades económicas e originar novas formas de subordinação, como produziu uma transformação qualitativa das dinâmicas de dominação cultural, que se tornaram mais subtis, menos evidentes, pois já não derivam directamente da estrutura de classes, tal como nos explica Fraser (2006).

\section{Conclusão}

Ao perspectivamos as escolas como instituições democráticas no contexto das complexas dinâmicas de poder constitutivas da realidade social e educativa, não podemos deixar de vislumbrar as práticas educativas como um importante desafio à injustiça social, o que nos remete de forma indiscutível para a necessidade de uma educação transformadora, em que as mais variadas formas de injustiça estejam presentes no trabalho e nas práticas escolares. Com efeito, trata-se de lhes garantir alguma notoriedade pública no seio das escolas que permita a construção de possibilidades de agência, um conteúdo político conducente à mudança que garanta a paridade participativa de todos na vida escolar. Isso significa que as instituições educativas precisam mergulhar profundamente nas comunidades locais em que se inserem, abrirem-se para trabalhar com e para todas as pessoas e instituições da comunidade interessadas na educação democrática e na construção de uma sociedade mais justa e igualitária, lidar com a realidade social injusta nas suas práticas educativas, promovendo o trabalho educativo como activismo para transformação social.

O contrário seria cair de forma irremediável naquilo que Enguita (2008) denomina de apropriação do espaço educativo público. Porém, é esta a situação que o autor acredita ser prevalente nas escolas actuais e que resulta do facto de os interesses e objectivos "públicos (os dos alunos, da comunidade envolvente e da sociedade em geral) ficarem subordinados aos interesses e objectivos privados (de cada professor) e corporativos (do conjunto dos professores)" (p. 99-100), unicamente comprometidos com o reforço da condição laboral da classe docente. Este seria um cenário 
mortal, tanto para a educação democrática como para a própria classe docente. Certamente, não é este o caminho a trilhar.

Os professores terão de criar as condições de diálogo e de cooperação conducentes à edificação de projectos educativos que resultem dos saberes, desejos, necessidades e aspirações das pessoas de cada comunidade local. Verdadeiros projectos educativos ao serviço do bem comum e da cultura democrática e não documentos inúteis que jazem de forma lamentável pelas estantes das escolas. O desenvolvimento dos currículos terá de partir necessariamente das vivências das crianças e dos jovens, da sua cultura, daquilo que os preocupa, que lhes interessa, sem evitar que o poder seja constitutivo da realidade social. As suas finalidades terão de traduzir os valores democráticos da liberdade, solidariedade e igualdade, no desafio permanente à injustiça social. O repto é enorme. Contudo, não o enfrentar destemidamente terá pesadas consequências para a concepção democrática da educação e para a liberdade individual e colectiva nas sociedades contemporâneas.

\section{Referências}

ALTHUSSER, L. Ideología y aparatos ideológicos del Estado. Buenos Aires: Nueva Visión, 1988.

BEAN, J. Curriculum integration. Designing the core of democratic education. New York: Teachers College Press, 1997.

BOURDIEU, P.; PASSERON, J.C. A reprodução: elementos para uma teoria do sistema de ensino. 4. ed. Petrópolis: Vozes, 2009.

CARNOY, M.; LEVIN, H.M. Schooling and work in the democratic State. Stanford: Stanford University Press, 1985.

CERTEAU, M. The practice of everyday life. Los Angeles: University of California Press, 1984.

DEWEY, J. Democracia e educação. Lisboa: Didáctica, 2007.

DEWEY, J. Educação e política. Igualdade, pragmatismo e democracia. Mangualde: Pedago, 2009.

ENGUITA, M.F. Será pública a escola pública? In: Paraskeva, J.M. (Org.). Educação e poder. Abordagens críticas e pós-estruturais. Mangualde: Pedago, 2008. p. 97-108.

FRASER, N. La justicia social en la era de la política de la identidad: redistribución, reconocimiento y participación. In: Fraser, N.; HonNeth, A. Redistribución o reconocimiento? Madrid: Morata; Fundación Paideia Galiza, 2006. p. 17-88. 
GIROUX, H. Border crossings: cultural workers and the politics of education. New York: Routledge, 1992.

GRAMSCI, A. Selections from the prison notebooks. New York: International Publishers, 1991.

KILPATRICK, W. O método de projecto. 2. ed. Mangualde: Pedago, 2006.

MOUFFE, C. Por um modelo agonístico de democracia. Mangualde: Pedago, 2006.

SANTOS, B.S. A gramática do tempo: para uma nova cultura política. Porto: Afrontamento, 2006.

SAVIANI, D. Escola e democracia. 40. ed. Campinas: Autores Associados, 2008.

THERBORN, G. La ideología del poder y el poder de la ideología. Madrid: Siglo XXI, 1987.

TORRES, J. El curriculum oculto. 6. ed. Madrid: Morata, 1998.

TORRES, J. Globalización e interdisciplinariedad: el curriculum integrado. 4. ed. Madrid: Morata, 2000.

TORRES, J. Educación en tiempos de neoliberalismo. Madrid: Morata, 2001.

TORRES, J. O cavalo de Tróia da cultura escolar. Mangualde: Pedago, 2010.

VIÑAO, A. Sistemas educativos, culturas escolares e reformas. Mangualde: Pedago, 2007.

ZINN, H.; MACEDO, D. Poder, democracia e educação. Mangualde: Pedago, 2007.

Recebido em janeiro de 2010.

Aprovado em dezembro de 2010. 